\title{
SUSTITUCIÓN LINGÜÍSTICA EN LAS COMUNIDADES DE HABLA ALICANTINAS*
}

\author{
FRANCISCO GIMENO MENENDEZ \\ (Universidad de Alicante)
}

A mis hermanos e hijo Vicente

\section{Introducción}

En sus estudios históricos y comparativos, los lingüistas de principios del siglo XIX se centraban en las lenguas nacionales (oficiales $y$ literarias), como objetivos primarios de investigación, y desatendian el hecho diferencial de los numerosos dialectos implicados. A fines de siglo, G. I. Ascoli, con la fundación de la revista Archivio Glottologico Italiano (1873), subrayó la importancia del registro hablado y de la observación directa del mismo, y la descripción de dialectos se hizo general, distinguiéndose dos enfoques distintos.

Uno fue la pura descripción de dialectos desde el punto de vista histórico, y mostraba el resultado del desarrollo fonético y morfológico desde el latín (o germánico, en su caso), en un espacio geográfico determinado, a fin de justificar la generalidad de las leyes fonéticas y señalar las fronteras de los dialectos (cfr. Barnils, 1913, 1914, 1929). Otra línea de investigación, denominada geografia lingüistica, acometió la descripción de las variantes dialectales -relacionándolas espacial-

* Expreso mi gratitud y reconocimiento a la Conselleria de Cultura, Educació i Ciència de la Generalitat Valenciana por la autorización para poder utilizar la encuesta y los resultados del Estudi sociologic sobre la problematica sociolingüistica a la Comunitat Valenciana _llevado a cabo por Molla, Alpera, Gimenoet al. (1985)_, así como a mis buenos amigos R. LI. Ninyoles, J. A. Viedma, M. Oliver y J. M. Aparicio. 
mente-, como opuestas a las leyes fonéticas y a la consiguiente creencia de fronteras dialectales de contorno regular y perfiles nitidos (cfr. Alcover, 1908; vid. Colomina, 1984a, 1984b, 1985a, 1985b, 1986).

1.1. Todos los lingüistas han reconocido que el lenguaje es un hecho social, pero no todos coinciden en el alcance de este hecho, y sobre todo, en la implicación y trascendencia de la acción de los factores sociales en los procesos más sistemáticos del cambio fonológico y sintáctico. Desde este punto de vista, W. Labov (1972, pp. 326 ss.) ha observado la polarización de los lingüistas del siglo pasado y del presente en dos grandes bloques: sociales (A) y asociales (B). Entre los primeros menciona a Whitney, Schuchardt, Meillet, Vendryes, Jespersen y Sturtevant. Entre los segundos cita a Paul, Sweet, Troubetzkoy, Bloomfield, Hockett, Martinet, Kurylowicz, Chomsky y Halle. Es posible, además, que vengan condicionadas ambas posiciones por prioridades metodológicas indiscutibles de un mayor grado de abstracción en unos momentos históricos determinados, y, por supuesto, que sean complementarias (vid. Gimeno, 1983a, 1984a).

Aunque los lingüistas del grupo A advierten la importancia de la diversidad lingüística y del multilingüismo, y se refieren para dar cuenta de la evolución a los modelos de ondas lingüísticas a través del tiempo, espacio y sociedad, sus argumentaciones aparecen muy limitadas, puesto que se basaban casi únicamente en una explicación intuitiva de algunos hechos accidentales, junto a los propios prejuicios del momento histórico. El grupo B, al contrario, sostiene la estrategia de una comunidad estrictamente monolingüe y perfectamente homogénea, y toma por modelo de evolución el árbol genealógico (Stammbaum). El cambio lingüístico se explica por factores puramente internos, estructurales o psicológicos, y consideran que la intervención de los factores sociales representa una interferencia extraña y disfuncional.

1.2. El objetivo especifico de este análisis responde a una revisión crítica de las hipótesis y evaluaciones elaboradas hasta hoy sobre el conflicto lingüístico valenciano l"de Alicante, a partir de una valoración de la encuesta y resultados del informe de Mollà, Alpera, Gimeno et al. (1985). El universo de estudio ha sido la población total de más de 16 años. El tamaño de la muestra ha sido de 1.605 entrevistas en todo el País Valenciano, distribuidas según un módulo fijo en cada

1 Vid. Fuster (1962); Aracil (1965, 1966, 1979, 1983); Mateo (1966); Ninyoles (1972 1976a, 1976b, 1977); Moliner et al. (1976); Ros (1979, 1982); Mira (1981); Alpera (1981); Montoya (1984, 1986b); Pitarch (1984); Gómez (1984); Gimeno (1982a, 1982b, 1986a). 
región y un número proporcional a su población, a fin de obtener resultados significativos a nivel regional y comarcal, fijando una corección final de equilibrio. Supone un margen de confianza del $95.5 \%$ y un margen de error del $\pm 2,5 \%$.

De acuerdo con el Nomenclàtor geogràfic del País Valencià (1970) se han establecido 6 regiones: Alacant, Alcoi-Gandia, València, CasteIló, Requena-Sogorb y Oriola. La región de Alacant comprende las comarcas de la Marina Baixa, l'Alacantí, el Baix Vinalopó y les Valls del Vinalopó. La región de Alcoi-Gandia incluye la Marina Alta, el Comtat, l'Alcoià, la Vall d'Albaida y la Safor. Y la región de Oriola abarca las comarcas de el Baix Segura, el Vinalopó Mitjà (Asp y Montfort) y l'Alt Vinalopó (Elda, les Salines, Villena y Sax). Nuestro trabajo se limita obviamente a la primera y tercera regiones (Alacant y Oriola), aunque el propio estudio del conflicto lingüístico valenciano nos obligará a establecer frecuentes análisis comparativos y contrastivos con la segunda (Alcoi-Gandia) y el resto de las regiones del País Valenciano. Los puntos de la muestra se determinaron de manera aleatoria para cada región y comarca. En la selección de encuestados se combinaron el sistema de «ruta aleatoria» $y$ el de «cuotas» de edad y sexo. Las encuestas se realizaron durante los meses de verano de 1985.

\section{Multilectismo de las comunidades de habla alicantinas}

A falta todavia de la encuesta definitiva sobre la regla variable del seseo valenciano, nuestra propuesta pasa por la determinación metodológica de la aplicación del concepto de comunidad de habla en función de la densidad de comunicación a nuestro contexto social, a partir de la evaluación de la actitud lingüistica sobre dicha variable (pregunta $n .{ }^{\circ} 32$, vid. tabla $\left.\mid\right)^{2}$. La actitud lingüistica respecto del seseo valenciano en función de las regiones valencianas nos muestra una actitud negativa general en todas ellas (índice ponderado total de .3) y superiores en

2 Dicha pregunta se formuló así: Li agrada que quan parla o sent parlar castellà es note l'accent valencià? (per exemple, "cossinero"' ¿Le complace que al hablar u oir hablar castellano se note el acento valenciano? ( $\boldsymbol{p}$. ej. "cosinero»). Las respuestas se limitaron a: Si, no, indiferent i no sap o no contesta/Si, no, indiferente y no sabe o no contesta. He asignado los valores de 0 y 1 a no y si, respectivamente. Ya que la indiferencia no puede considerarse como actitud lingüistica, la he valorado negativamente. Las frecuencias de no sabe o no contesta no se han incluido en los cálculos estadísticos. Por otra parte, un punto de partida basado en la diferenciación del País Valenciano en dos áreas lingüísticas, como es la postura de los autores del citado Nomenclator geogràfic, nos garantiza la mayor objetividad para completarlo (vid. Juan i Fenollar, 1981; Gimeno, 1986b). No obstante, nuestro trabajo viene moderado por la inclusión de la Marina Baixa en la región de Alacant, la cual desestima la frontera histórica Biar-Busot (vid. Colomina, 1985a, pp. 148 ss.). 
las regiones castellanohablantes (Requena-Sogorb y Oriola). Dichos índices diferencian dos zonas alicantinas: a) área de actitud menos negativa e igual al índice general del País Valenciano: región de Alacant (índice de .3), y b) área de actitud más negativa e inferior a ese índice general: Oriola (índice de .1).

TABLA I

Indices de actitud lingüistica hacia el seseo valenciano en función de las regiones valencianas (ordenadas de mayor a menor)

\begin{tabular}{lrrrrrrrrr}
\hline & & \multicolumn{2}{c}{ Positiva } & \multicolumn{2}{c}{ Negativa } & \multicolumn{2}{c}{ Indiferente } & \\
\cline { 3 - 7 } Regiones & Total & N & $\%$ & N & $\%$ & N & $\%$ & Indice \\
\hline València & 444 & 176 & 37 & 86 & 18 & 182 & 38 & .4 \\
Castelló & 226 & 83 & 36 & 41 & 18 & 102 & 45 & .4 \\
Alacant & 282 & 83 & 29 & 43 & 15 & 156 & 55 & .3 \\
Alcoi-Gandia & 215 & 63 & 28 & 47 & 21 & 105 & 46 & .3 \\
Requena-Sogorb & 179 & 45 & 25 & 41 & 23 & 93 & 51 & .2 \\
Oriola & 203 & 19 & 9 & 18 & 9 & 166 & 81 & .1 \\
\hline TOTAL & 1.549 & 469 & 29 & 276 & 17 & 804 & 50 & .3 \\
\hline
\end{tabular}

La hipótesis nula de independencia puede ser rechazada con seguridad (probabilidad inferior a .001), y, por consiguiente, la dependencia entre la actitud hacia el seseo valenciano y los hablantes de las regiones de Alacant y Oriola es real (por razones obvias, omito el detalle de la inferencia estadística). Por otro lado, las diferencias entre las proporciones correspondientes de población de los hablantes que tienen actitudes positivas o negativas son estadísticamente significativas: región de Alacant $(-.57 ;-.23)$ y de Oriola $(-.93 ;-.69)$ para un nivel de confianza del $95 \%$. Asimismo, las diferencias entre las proporciones de población de los hablantes de las regiones de Alacant u Oriola que tienen actitudes positivas son estadisticamente significativas $(.07 ; .19)$, pero no lo son las actitudes negativas $(-.09 ; .15)$, ya que el intervalo incluye el cero, para el mismo nivel de confianza del $95 \%$ (vid. Johnson y Wichern, 1982, pp. 205 ss.). Es decir, la fracción de población que tiene actitud positiva hacia el seseo valenciano en la región de Alacant es significativamente superior a la fracción correspondiente de población de la región de Oriola.

Por otra parte, si tenemos en cuenta que la región de Oriola engloba 
la comarca del'Alt Vinalopó, y, en particular, Villena y Sax, donde no se da la regla variable del seseo valenciano, podríamos seguir partiendo todavía de la hipótesis de diferenciar actualmente, como mínimo, tres comunidades de habla:

1) Área de l'Alacantí, el Baix Vinalopó y les Valls del Vinalopó, es decir, la región de Alacant excepto la comarca de la Marina Baixa;

2) Area de el Baix Segura y el Vinalopó Mitjà, incluyendo los núcleos de Elda y les Salines, y

3) Area de l'Alt Vinalopó propiamente dicha, es decir, Villena y Sax.

2.1. La principal hipótesis que hemos mantenido ha sido el multilectismo de las comunidades de habla alicantinas. Con otras palabras, las comunidades de habla alicantinas serían multilectales, ya que se basarian en una covariación entre los dos (sub)sistemas de un único repertorio lingüístico. De esta manera, dicho repertorio identificaría la operatividad de una competencia comunicativa colectiva compleja que incluiría todos los sociolectos de nuestro contexto social (valenciano, valenciano alicantino, murciano alicantino, murciano y castellano estándar), y podría darse una comunidad mayor de integración simbólica, por encima de las dos comunidades idiomáticas (vid. Gimeno, 1986a, par. 3). Entre otras cosas, implicaría que el monolingüismo catalán o castellano, en términos absolutos, sería prácticamente inexistente o aislado y la mayor parte de la población respondería a un esquema comunicativo de bilingüismo activo o pasivo (sesquilingüismo).

La competencia comunicativa valenciana en función de las regiones valencianas aparece analizada en los índices de comprensión oral subjetiva del valenciano (pregunta . $^{\circ} 1 \mathrm{a}$, vid. tabla II) ${ }^{3}$ y en los índices compuestos de la competencia comunicativa subjetiva del valenciano (preguntas n. ${ }^{\circ 5} 1 \mathrm{a}-4 \mathrm{a}$, vid. tabla lil) ${ }^{4}$. En la primera, el nivel de no comprensión oral subjetiva del valenciano en la región de Alacant es muy bajo $(8 \%)$ e inferior al total del País Valenciano $(11 \%)$. La región de Oriola ofrece el mayor porcentaje de ausencia de comprensión del valenciano de todo

3 La pregunta se formuló así: Entén vosté el valencià?¿¿Entiende Vd. el valenciano? Las respuestas se limitaron a: Gens, un poc, prou bé $i$ no contesta/Nada, un poco, muy bien y no contesta. He asignado los valores de 0,1 y 2 a nada, un poco y muy bien, respectivamente.

4 La pregunta $n^{\circ}$ 2a se formuló asi: Sap parlar vosté valencia?/¿Sabe hablar Vd. valenciano? Las preguntas $3 a$ y 4 a se formularon asi: Sap llegir/escriure vosté en valencià?// ¿Sabe leer/escribir Vd. en valenciano? Las respuestas se limitaron a: Gens, un poc, prou bé $i$ no contesta/Nada, un poco, muy bien y no contesta. He asignado los mismos valores que en la nota precedente, y las frecuencias de no contesta no se han incluido en los cálculos estadísticos. 
el País Valenciano (41\%), aunque la mayoria sí que lo entiende (59\%). Con todo, dicho porcentaje es más bien un claro exponente de una actitud receptiva negativa hacia el valenciano que una medida de la comprensión valenciana oral subjetiva. La indudable existencia de variedades intermedias o de transición cuestionan que la falta de entendimiento hacia el valenciano responda a un hecho lingüístico, y en su defecto se trate de un reflejo de actitudes primordialmente sociales (vid. infra, par. 4).

TABLA \|

Indices de comprensión oral subjetiva del valenciano en función de las regiones valencianas (ordenadas de mayor a menor)

\begin{tabular}{|c|c|c|c|c|c|c|c|c|}
\hline \multirow[b]{2}{*}{ Regiones } & \multirow[b]{2}{*}{ Total } & \multicolumn{2}{|c|}{ Nada } & \multicolumn{2}{|c|}{ Un poco } & \multicolumn{2}{|c|}{ Muy bien } & \multirow[b]{2}{*}{ Índice } \\
\hline & & $\mathbf{N}$ & $\%$ & $\mathbf{N}$ & $\%$ & $\mathbf{N}$ & $\%$ & \\
\hline Alcoi-Gandia & 229 & 1 & 0 & 18 & 8 & 210 & 92 & 1.9 \\
\hline Castelló & 228 & 5 & 2 & 24 & 11 & 199 & 87 & 1.9 \\
\hline València & 480 & 23 & 5 & 64 & 13 & 393 & 82 & 1.8 \\
\hline Alacant & 283 & 22 & 8 & 65 & 23 & 196 & 69 & 1.6 \\
\hline Requena-Sogorb & 181 & 41 & 23 & 71 & 39 & 69 & 38 & 1.2 \\
\hline Oriola & 204 & 84 & 41 & 67 & 33 & 53 & 26 & .8 \\
\hline TOTAL & 1.605 & 176 & 11 & 309 & 19 & 1.120 & 70 & 1.6 \\
\hline
\end{tabular}

La hipótesis nula de independencia puede ser rechazada con toda seguridad (probabilidad muy inferior a .001), y, por consiguiente, la dependencia entre la comprensión oral subjetiva del valenciano y los hablantes de las regiones de Alacant y Oriola es bien real. Por otro lado, las diferencias entre las proporciones de población de los hablantes de la región de Alacant que no comprenden «nada», comprenden «un poco» o «muy bien» son estadísticamente significativas: «nada»-«un poco» $(-.25 ;-.05)$, «nada»-«muy bien» $(-.72 ;-.5)$ y «un poco»-«muy bien» $(-.61 ;-.31)$, para un nivel de confianza del $95 \%$. Sin embargo, las diferencias entre las proporciones de población de los hablantes de la región de Oriola que no comprenden "nada", comprenden «un poco» o «muy bien» no son ninguna de ellas estadísticamente significativas, ya que los intervalos correspondientes incluyen el cero: «nada»-«un poco» $(-.1 ; .26)$, «nada»-«muy bien» $(-.02 ; .32)$ y «un 
poco»-«muy bien» $(-.09 ; .23)$, para el mismo nivel de confianza del $95 \%$.

Es decir, inferimos un modelo teórico que aprecia la significación global de la comprensión oral subjetiva del valenciano entre los hablantes de la región de Alacant, y la inexistencia de una fracción de población estadísticamente significativa entre los hablantes de la región de Oriola que no entienda el valenciano. Y de este modo, obtenemos la primera confirmación de la hipótesis del multilectismo de las comunidades de habla alicantinas.

Por su parte, en la tabla III es perceptible, en líneas generales y a nivel descriptivo, la correlación decreciente de los sucesivos índices simples de comprensión, habla, lectura y escritura con la ausencia de normalización lingüística ( $\mathrm{y}$, en particular, con la exclusión del valenciano del ámbito de la educación "formal») en todas las regiones valencianas, incluida Oriola. El mismo orden de las regiones nos pone de manifiesto el proceso geográfico de castellanización de la sociedad valenciana (de mayor a menor): Oriola, Alacant, València, Castelló y AlcoiGandia. Mientras que los índices de escritura sólo descartan este tipo de conocimiento en las regiones de A/coi-Gandia, Castelló, València y Alacant (.5 o inferiores), el índice simple de comprensión oral subjetiva del valenciano en la región de Oriola es el único significativo (.8).

TABLA III

Indices compuestos de la competencia comunicativa subjetiva del valenciano en función de las regiones valencianas (ordenadas de mayor a menor)

\begin{tabular}{lccccc}
\hline Regiones & Comprensión & Habla & Lectura & Escritura & $\begin{array}{c}\text { índice } \\
\text { comp. }\end{array}$ \\
\hline Alcoi-Gandia & 1.9 & 1.8 & 1 & .5 & 1.3 \\
Castelló & 1.9 & 1.6 & 1 & .4 & 1.2 \\
València & 1.8 & 1.5 & 1.1 & .5 & 1.2 \\
Alacant & 1.6 & 1.2 & .8 & .3 & 1 \\
Requena-Sogorb & 1.2 & .6 & .3 & .1 & .5 \\
Oriola & .8 & .4 & .3 & .1 & .3 \\
\hline TOTAL & 1.6 & 1.3 & .8 & .3 & 1 \\
\hline
\end{tabular}


2.2. Otra posibilidad de corroborar ese aserto se obtiene con el análisis de los indices de comprensión oral subjetiva en función del lugar de nacimiento de los encuestados (vid. tabla IV). El índice simple de la comprensión oral subjetiva de los inmigrantes castellanohablantes de todo el País Valenciano es superior al de los autóctonos castellanohablantes (1.3 frente a 1), y nos indica un cierto grado de asimilación lingüistica e integración cultural. En este caso, el sesquilingüismo de dichos inmigrantes -en oposición al de los citados autóctonos - responde a un hecho lingüistico y a una actitud receptiva positiva hacia la variedad lingüistica y cultura anfitrionas ( $83 \%$ y $69 \%$, respectivamente). Asimismo, el dato definitivo que pone en evidencia el prejuicio hacia el vernáculo valenciano y el conflicto de lealtad lingüística de los autóctonos castellanohablantes, hasta el punto de afectar la inteligibilidad mutua, es su mayor porcentaje de nula comprensión oral subjetiva del valenciano que el de los inmigrantes castellanohablantes (30\% frente a $17 \%$ ).

La hipótesis nula de independencia puede ser rechazada con toda seguridad (probabilidad inferior a .001), y, por consiguiente, la hipótesis de una diferencia significativa en la comprensión oral subjetiva del valenciano en función del lugar de nacimiento se puede mantener. Por otro lado, las diferencias entre las proporciones correspondientes de población de los hablantes nacidos en los diversos municipios no son uniformes. En el caso de los hablantes nacidos en municipios valencianohablantes del País Valenciano, las diferencias entre las proporciones de población de los hablantes que no comprenden "nada", comprenden «un poco» o «muy bien» son estadísticamente significativas: "na-

\section{TABLA IV}

Indices de comprensión oral subjetiva del valenciano en función del lugar de nacimiento (ordenado de mayor a menor)

\begin{tabular}{lrrrrrrrrr}
\hline & & \multicolumn{2}{c}{ Nada } & \multicolumn{2}{c}{ Un poco } & \multicolumn{2}{c}{ Muy bien } & \\
\cline { 3 - 8 } Municipio & Total & N & $\%$ & N & $\%$ & N & $\%$ & indice \\
\hline Val. del P.V. & 931 & 14 & 1 & 62 & 7 & 855 & 92 & 1.9 \\
Cat. fuera P.V. & 13 & 0 & 0 & 2 & 15 & 11 & 85 & 1.8 \\
Cast. fuera P.V. & 228 & 40 & 17 & 77 & 34 & 111 & 49 & 1.3 \\
Cast. del P.V. & 355 & 108 & 30 & 136 & 38 & 111 & 31 & 1 \\
\hline TOTAL & 1.527 & 162 & 11 & 277 & 19 & 1.088 & 70 & 1.6 \\
\hline
\end{tabular}


da»-«un poco" $(-.85 ;-.25)$, "nada»-«muy bien» $(-.93 ;-.87)$ y «un poco»-«muy bien» $(-.9 ;-.8)$, para un nivel de confianza del $95 \%$. En el caso de los hablantes nacidos en municipios castellanohablantes del País Valenciano, las diferencias no son ninguna de ellas estadísticamente significativas: «nada»-«un poco» $(-.21 ; .05)$, «nada»-«muy bien» $(-.14 ; .12)$ y «un poco»-«muy bien» $(-.06 ; .2)$, para el mismo nivel de confianza del $95 \%$. En el caso de los hablantes nacidos en municipios catalanohablantes de fuera del País Valenciano, son estadísticamente significativas la diferencia de «nada»-«muy bien» $(-1.1 ;-.55)$ y de «un poco»-«muy bien» $(-1.3 ;-.09)$, pero no lo es la diferencia de «nada»-«un poco» $(-.45 ; .15)$, para el mismo nivel de confianza. $Y$ en el caso de los hablantes nacidos en municipios castellanohablantes de fuera del Pais Valenciano, son estadísticamente significativas la diferencia de «nada»-«un poco» $(-.31 ;-.03)$ y de «nada»-«muy bien» $(-.47$; -.17), sin embargo no lo es la diferencia de "un poco»-«muy bien» $(-.33 ; .03)$, para el mismo nivel de confianza del $95 \%$.

Finalmente, una probable verificación se nos ofrece en la confrontación de los datos obtenidos con los índices de comprensión oral subjetiva de la variedad catalana estándar en función de las regiones valencianas (pregunta $n .{ }^{\circ} 8$, vid. tabla $\left.V\right)^{5}$. El índice ponderado de la comprensión catalana estándar en la región de Alacant es igual al indice general de comprensión oral subjetiva del País Valenciano (1), y el índice de la región de Oriola deja de ser descriptivamente significativo (.3), si bien dichos índices incluyen también un componente de una actitud receptiva negativa hacia el catalán estándar. Así y todo, las variedades alicantinas se pueden ordenar gráficamente a lo largo de un continuo geográfico y social catalano-castellano, en el que cada par de variedades adyacentes son mutuamente inteligibles, aunque no lo son los que se hallan en los extremos opuestos de esa cadena, o sea, el murcianohablante de la región de Oriola comprende las variedades valencianas (alicantina y común), aunque no la catalana estándar (vid. fig. 1).

La hipótesis nula de independencia puede ser rechazada con seguridad (probabilidad inferior a .001), y, por consiguiente, la dependencia entre la comprensión oral subjetiva de la variedad catalana estándar y los hablantes de las regiones de Alacant y Oriola es real. Por otro lado, las diferencias entre las proporciones de población de los hablantes de

5 La pregunta se formuló así: Quan li parla un català, vosté l'entén?/¿Cuando le habla un catalán, Vd. lo entiende? Las respuestas se limitaron a: Gens, un poc, prou bé, no n'he tingut oportunitat i no contesta/Nada, un poco, muy bien, no he tenido oportunidad de ello y no contesta. No se han incluido las frecuencias ni los cálculos estadísticos de las dos últimas respuestas por su minima incidencia. 
la región de Alacant que no comprenden "nada", comprenden "un poco» o «muy bien» no son uniformes, de manera que son estadísticamente significativas la diferencia de «nada»-«un poco» $(-.37 ;-.05)$ y de «un poco»-«muy bien» $(.08 ; .38)$, pero no lo es la diferencia de «nada»«muy bien» $(-.11 ; .15)$, para un nivel de confianza del $95 \%$. Sin embargo, las diferencias entre las proporciones de población de los hablantes de la región de Oriola que no comprenden "nada», comprenden «un poco» o «muy bien» son estadísticamente significativas: «nada»-«un poco» $(.31 ; .67)$, «nada»-«muy bien» $(.52 ; .78)$ y «un poco»«muy bien» $(.05 ; .27)$, para el mismo nivel de confianza del $95 \%$.

\section{TABLA V}

Indices de comprensión oral subjetiva de la variedad catalana estándar en función de las regiones valencianas

(ordenadas de mayor a menor)

\begin{tabular}{lrrrrrrrrr}
\hline & & \multicolumn{2}{c}{ Nada } & \multicolumn{2}{c}{ Un poco } & \multicolumn{2}{c}{ Muy bien } & \\
\cline { 3 - 8 } Regiones & Total & \multicolumn{1}{c}{$\mathbf{N}$} & $\%$ & N & $\%$ & N & $\%$ & Índice \\
\hline Castelló & 226 & 27 & 12 & 64 & 28 & 135 & 59 & 1.5 \\
València & 450 & 87 & 18 & 162 & 34 & 201 & 42 & 1.3 \\
Alcoi-Gandia & 219 & 34 & 15 & 99 & 43 & 86 & 38 & 1.2 \\
Alacant & 272 & 75 & 27 & 30 & 46 & 67 & 24 & 1 \\
Requena-Sogorb & 167 & 83 & 46 & 63 & 35 & 21 & 12 & .6 \\
Oriola & 196 & 140 & 69 & 44 & 22 & 12 & 6 & .3 \\
\hline TOTAL & 1.530 & 446 & 28 & 562 & 35 & 522 & 33 & 1 \\
\hline
\end{tabular}

2.3. En suma, los distintos análisis de la competencia comunicativa subjetiva del valenciano en función de las regiones valencianas nos ratifican la hipótesis de que las comunidades de habla alicantinas son multilectales $^{6}$, y nos ofrecen la posibilidad de ordenar descriptivamente las

6 Las relaciones entre los informes personales acerca de la conciencia y comportamiento lingúisticos y las observaciones de los investigadores sobre los mismos han de ser estudiadas todavia minuciosamente, aunque está hoy mucho más claro que hace unos pocos años que la correlación puede ser muy alta. No obstante, depende de la clase de datos de la conciencia y comportamiento linguísticos solicitados y de la condición de los sujetos examinados (vid. Fishman, 1966; Fishamn, Cooper, Ma et al., 1971, pp. 105 ss.; Weydt y SchliebenLange, 1981 , pp. 120 ss.). Algunos trabajos empíricos han demostrado que los datos referentes a la comprensión oral objetiva no modifican los resultados de la comprensión oral sub- 
variedades alicantinas, como casos particulares de «gramáticas variacionales", en dos variedades intermedias o "gramáticas de transición", a saber: a) valenciano-alicantina, que posee una competencia activa de la variedad valenciana, y b) murciano-alicantina, que tiene una competencia pasiva de las variedades valencianas, aunque no de la variedad catalana estándar. Ahora bien, la presencia de un haz de isoglosas superpuestas para un cierto número de propiedades (ausencia de diptongación ié $(<\dot{E})$ y ué $(<\circlearrowright)$, conservación de $s$ - sonora, palatalización de L- inicial, etc.) reagrupa diáfanamente las variedades catalanas frente a las castellanas.

DIASISTEMA CATALÁN

DIASISTEMA CASTELLANO

\begin{tabular}{|c|c|c|c|c|c|}
\hline \multirow[t]{2}{*}{$\begin{array}{l}\text { Catalán } \\
\text { estándar }\end{array}$} & Valenciano & $\begin{array}{l}\text { Valenciano } \\
\text { alicantino }\end{array}$ & $\begin{array}{l}\text { Murciano } \\
\text { alicantino }\end{array}$ & Murciano & $\begin{array}{l}\text { Castellano } \\
\text { estándar }\end{array}$ \\
\hline & & $\begin{array}{l}\text { Valenciano } \\
\text { «apitxat» }\end{array}$ & $\begin{array}{l}\text { Aragonés } \\
\text { valenciano }\end{array}$ & Aragonés & \\
\hline
\end{tabular}

Fig. 1. Situación descriptiva de las variedades alicantinas y valencianas dentro del continuo geogrático y social catalano-castellano.

\section{Sustitución lingüística en las relaciones económicas y formales}

En líneas generales, la covariación de dos o más (sub)sistemas en el repertorio lingüistico de una comunidad de habla debe inscribirse dentro de las soluciones siguientes: a) interferencia y cambio de norma, entendidos como uso alternativo de dos variedades en el mismo enunciado, oración, constituyente o segmento; b) amalgama, o reestructuración lingüística de dos variedades particulares en una nueva gramática, y c) sustitución lingüística, como abandono de una variedad particular (B) en beneficio de otra (A) (cfr. Weinreich, 1968, p. 650). El

jetiva (vid. Turell, 1984, pp. 162 ss.). Con todo, la provisión de suficiente evidencia empírica para demostrar la existencia de la gramática multilectal entraña un reto teórico y metodológico, dentro de un maco general de multilingüismo y multilectismo (vid. Bailey, 1972, 1973; Labov, 1973; Bickerton, 1973, 1975; Rona, 1976; Berdan, 1977; Heidelberger Forschungsprojeck "Pidgin-Deutsch», 1978; Amastae, 1981; Trudgill, 1982; Gimeno, 1985). 
cambio lingüistico en curso (o en marcha) seria un caso particular de interferencia y cambio de norma.

Las dos primeras (interferencia y cambio de norma) pueden relacionarse con la amalgama y con el grado y dirección de la sustitución lingüística, y hasta es posible que aquéllas, como cuestiones parciales, sólo tengan cumplida consideración dentro de la amplia y compleja interrelación de los componentes de las otras dos ${ }^{7}$. La criollización y la sustitución lingüística representan dos dinámicas mutuamente excluyentes - para algunos, según el grado de afinidad lingüística (máxima o nula, res activamente)-, si bien las relaciones y conexiones entre ambos procesos (y a partir del cambio de norma) pueden ofrecer una aportación especial, en función de las diversas situaciones sociolingüísticas (vid. Montoya, 1986a; Gimeno, 1981, 1985).

3.1. Es evidente que en el conflicto lingüistico valenciano de las comunidades de habla alicantinas se dan unas coordenadas de interferencia y cambio de norma y de sustitución lingüística catalano-casteIlana. Ahora bien, las mismas fases del conflicto (oposición sociolingüística castellano estándar/valenciano alicantino y castellano estándar/murciano alicantino), el multilectismo de sus comunidades de habla, los análisis de regla variable y las escalas de implicación, etc. nos permiten vislumbrar una cierta dinámica de la criollización, debido no tanto a la afinidad lingüistica, como a la semejanza misma de los procesos implicados - no de los resultados -, a partir de la covariación de dos (sub)sistemas en el único repertorio lingüístico de las comunidades de habla, y de las variedades intermedias o "gramáticas de transición" dentro del continuo geolectal y sociolectal catalano-castellano. Es más, es posible que sea el último principio general e histórico de la evolución lingüística en general.

El conflicto lingüístico valenciano de las comunidades de habla alicantinas constituye un proceso histórico complejo y de larga duración, probablemente desde el siglo $\mathrm{XV}$, en el cual se encuentran inmersos variedades lingüísticas y hablantes. El estudio de la conservación y sustitución lingüísticas trata de llegar a una determinación de la situación sociolingüística actual de las comunidades de habla alicantinas. Las preferencias lingüísticas acumuladas en muchos individuos se transforman en procesos de mantenimiento o sustitución. De esta ma-

7 La sustitución lingüistica ha sido desgraciadamente poco estudiada y simplificada dentro de la problemática de la historia de la lengua (cfr. Várvaro, 1973, pp. 519 s.; vid. Aracil, 1965, 1979). En nuestro contexto histórico-social valenciano ha habido varios procesos sucesivos de sustitución linguística (latinización, arabización, catalanización y castellanización). 
nera, la configuración de predominio permite valorar el grado y localización del bilingüismo, sobre el análisis de las posibles fuentes y ámbitos de variación en el comportamiento lingüístico dentro de las comunidades de habla, y puede reducirse a un sencillo índice de dirección de cualquier tendencia desde el bilingüismo al monolingüismo entre dos puntos en el tiempo y/o espacio. Aunque el estudio de la conservación y sustitución lingüisticas se ocupe, además y básicamente, de la correlación con los procesos psicológicos, sociales y culturales implicados.

3.2. El proceso de la sustitución lingüistica (y aculturación) catalana ha seguido unas dinámicas temporales, geográficas y sociales (cuantitativas y cualitativas) muy desiguales. La regresión histórica valenciana del Baix Segura —excepto Guardamar y Barba-roja (término municipal de Oriola) - y de Elda, les Salines, Asp y Montfort, en el Vinalopó Mitjà, a principios del siglo XVIII, fue debido sobre todo a la expulsión de los moriscos (1609-1614), peste de Oriola (1648) e inmigración castellanohablante de los vecinos y próximos núcleos murcianos (vid. Montoya, 1982, 1985; Gimeno, 1983b, 1984b).

El proceso social de castellanización de la sociedad valenciana ha seguido, según Ninyoles (1972, pp. 101 ss.), tres direcciones básicas: a) horizontal y selectiva (siglos XVI-XIX); b) descendente espontánea (siglo XIX), y c) totalizadora (aparición de los medios de comunicación de masas). La presión formal del castellano, impuesto en los ámbitos públicos tras la pérdida de la oficialidad del catalán por el decreto de Nueva Planta (1707), supuso el divorcio general de lengua y cultura. Hasta el segundo tercio del siglo XIX el proceso de castellanización social no llegaria a interesar a un sector de la oligarquía terrateniente, clases medias y pequeña burguesía, los cuales eran motejados por los alicantinos con el nombre de l'aristocràcia del bacallà. El efecto nivelador de los medios de comunicación y la exclusión del valenciano de la esfera pública —prensa, radio, televisión, educación, etc. — vendrian a consolidar aquel proceso durante la época actual, independizándose de la movilidad social e implicando a los estratos inferiores de la sociedad (vid. Aracil, 1968).

3.3. La modernización actual y creciente de la sociedad alicantina ha producido la restricción del valenciano a una situación minoritaria. El recurso de adoptar el castellano como una típica hipótesis cero, válida en principio y en general, confina al valenciano a un ámbito familiar e informal, dentro de una recesión escalonada. La cotidianidad del castellano dentro de la vida de los valencianohablantes debilita el 
bilingüismo activo en pasivo, y pertenece ya a un proceso de instauración del monolingüismo. La socialización y educación de los hijos en castellano culminaria la sustitución lingüística, y consumaría el conflicto lingüístico valenciano (vid. Aracil, 1983, pp. 171 ss.).

La situación sociolingüística actual en función de la actuación comunicativa individual se presenta en términos de ámbitos de uso según la atención y formalidad prestadas al discurso (familiar, de ocio y tiempo libre, laboral y de intercambio económico). Dada la propia continuidad de dichos contextos, optamos por analizar los extremos opuestos del eje funcional de los registros, es decir, la actuación comunicativa bilingüe del ámbito familiar frente a la del ámbito de intercambios económicos en función de las regiones valencianas y de las clases sociales subjetivas, a fin de examinar visiblemente los propios términos de la dinámica sustitutiva del conflicto lingüistico en su contexto más informal y más formal.

3.4. La actuación comunicativa bilingüe del ámbito familiar (relación encuestado-padres, encuestado-hijos) en función de las regiones valencianas nos ofrece en general la configuración descriptiva de una comunidad bilingüe activa con predominio del castellano oral sobre el valenciano (índice compuesto general de 2.3, vid. tabla VI). Los índices compuestos ponderados de actuación bilingüe del ámbito familiar nos distinguen tres zonas: a) área de bilingüismo activo con claro predominio del valenciano oral: A/coi-Gandia (índice compuesto de 3.1), Castelló (2.7) y València (2.6); b) área de bilingüismo activo con predominio neto del castellano oral: Alacant (índice compuesto de 2.1), y c) área de bilingüismo pasivo con dominio del castellano: Oriola (índice compuesto de 1.1) y $R e-$ quena-Sogorb (1.1).

La dinámica paterna (encuestado-padres) contrasta con la filial (encuestado-hijos) y experimenta un descenso general en todas las regiones, sobre todo en la "variedad hablada con su pareja" y, en particular, en la región de Alacant (índice simple de 1.9). Dicha disminución paulatina de las tres generaciones (abuelos, padres e hijos) nos relaciona descriptivamente la sustitución lingüística (y la aculturación) en la actuación bilingüe del ámbito familiar con la socialización y educación de los hijos.

3.5. La actuación comunicativa bilingüe del ámbito familiar (relación paterna y filial) en función de las clases sociales subjetivas ${ }^{8}$ nos

8 Los datos de identificación y clasificación socioeconómica se establecieron en función de las variables sociales siguientes: a) edad, b) sexo, c) estado civil, d) lugar de nacimiento, e) procedencia de la familia, f) tiempo de residencia en el municipio, g) relación con el cabeza 


\section{TABLA VI}

Indices compuestos de la actuación comunicativa bilingüe del ámbito familiar en función de las regiones valencianas (ordenadas de mayor a menor)

\begin{tabular}{lccccccc}
\hline & \multicolumn{3}{c}{ Relación paterna } & \multicolumn{3}{c}{ Relación filial } & \\
\cline { 2 - 7 } Regiones & Padre & Madre & $\begin{array}{c}\text { Entre } \\
\text { ellos }\end{array}$ & Hijo & Hija & Pareja & $\begin{array}{l}\text { Indice } \\
\text { comp. }\end{array}$ \\
\hline Alcoi-Gandia & 3.1 & 3.2 & 3.3 & 3.1 & 3.1 & 3.1 & 3.1 \\
Castelló & 2.8 & 2.8 & 2.8 & 2.8 & 2.7 & 2.7 & 2.7 \\
València & 2.7 & 2.7 & 2.8 & 2.7 & 2.7 & 2.5 & 2.6 \\
Alacant & 2.2 & 2.2 & 2.4 & 2.1 & 2.1 & 1.9 & 2.1 \\
Oriola & 1.2 & 1.3 & 1.3 & 1.1 & 1.1 & 1.1 & 1.1 \\
Requena-Sogorb & 1.2 & 1.2 & 1.2 & 1.1 & 1.1 & 1.1 & 1.1 \\
\hline TOTAL & 2.3 & 2.3 & 2.4 & 2.3 & 2.3 & 2.2 & 2.3 \\
\hline
\end{tabular}

muestra hasta qué punto la sustitución lingüística se ha impuesto como exigencia del cambio social, y si se ha independizado de dicha movilidad social (vid. tabla VII). Los índices compuestos de la actuación bilingüe del ámbito familiar nos ofrecen unas ponderaciones de la clase media y baja inferiores a la general (2.1 frente a 2.3). El peso específico de la inmigración castellanohablante está influyendo, sin duda, en dicho total de la clase social baja. Los índices simples de actuación bilingüe de la relación filial nos ofrecen de un modo descriptivo la dinámica sustitutiva de la clase media en la «variedad hablada con las hijas» $y$, sobre todo, con la pareja (2.1 y 1.9, respectivamente). No obstante, la sustitución lingüística implica también a los estratos inferiores, dentro de una última fase totalizadora (así, p. ej., la clase media baja presenta un índice compuesto de 2.4 frente a 2.5 en la correspondiente relación filial o paterna).

\footnotetext{
de familia, h) número de componentes de la familia, i) nivel de estudios, j) situación laboral actual, k) actividad principal, I) nivel de ingresos familiar, $m$ ) equipamiento del hogar, $n$ ) clase social subjetiva, y o) hábitat. A falta de un punto de vista crítico y dinámico de historia y sociedad, de un indice global y en vista de que el nivel de ingresos es poco fiable he seleccionado la socorrida "clase social subjetiva» $y$ «actividad principal». Es muy posible que los parámetros últimos de la sustitución lingüistica no estén en esos factores, sino en la propia relación entre redes sociales, identidad y estrategias comunicativas (vid. Gal, 1979; Milroy, 1980, 1982; Poplack, 1986; Gimeno, 1987, par. 3.2.).
} 
TABLA VII

Indices compuestos de la actuación comunicativa bilingüe del ámbito familiar en función de las clases sociales subjetivas

\begin{tabular}{|c|c|c|c|c|c|c|c|}
\hline \multirow[b]{2}{*}{ Clases sociales } & \multicolumn{3}{|c|}{ Relación paterna } & \multicolumn{3}{|c|}{ Relación filial } & \multirow[b]{2}{*}{$\begin{array}{l}\text { Indice } \\
\text { comp. }\end{array}$} \\
\hline & Padre & Madre & $\begin{array}{l}\text { Entre } \\
\text { ellos }\end{array}$ & Hijo & Hija & Pareja & \\
\hline \multicolumn{8}{|l|}{ Alta/ } \\
\hline Media alta & 2.4 & 2.4 & 2.5 & 2.2 & 2.1 & 2.2 & 2.3 \\
\hline Media & 2.2 & 2.2 & 2.2 & 2.3 & 2.1 & 1.9 & 2.1 \\
\hline Media baja & 2.5 & 2.5 & 2.5 & 2.4 & 2.5 & 2.3 & 2.4 \\
\hline Baja & 2.1 & 2.1 & 2.2 & 2.1 & 2.2 & 2.1 & 2.1 \\
\hline TOTAL & 2.3 & 2.3 & 2.4 & 2.3 & 2.3 & 2.2 & 2.3 \\
\hline
\end{tabular}

Otro modo de aproximarnos a dicho proceso se obtiene a partir del análisis de la actuación comunicativa bilingüe del ámbito familiar (relación paterna y filial) en función de la actividad principal del encuestado (vid. tabla VIII). Los índices compuestos de los sectores de "servicios" y "estudiantes" de todo el País Valenciano ofrecen unas ponderaciones inferiores a las demás y a la general (2.1 frente a 2.3), descontando obviamente el sector de la «construcción» (2). F. Mira (1981, pp. 117 ss.) ha ofrecido una distinción de "ocupaciones no móviles" (agricultores, empresarios y comerciantes) y "ocupaciones móviles» (empleados y profesiones liberales) entre los valencianohablantes del País Valenciano, y sus correspondientes medias diferencian claramente a unas de otras $(64 \%$ frente a $56.8 \%$ para la provincia de Alicante, vid. Gimeno, 1986a, par. 2.1).

Una explicación puede residir, por un lado, en la movilidad ascendente de los hijos de inmigrantes, y por otro, ante el hecho de que ias ocupaciones administrativas y profesionales ofrecen el mayor número de valencianos que adoptan el castellano como lengua familiar/signo de ascenso social. Desde este punto de vista, los índices de los sectores de "servicios» y «estudiantes" ratifican descriptivamente esa cierta movilidad, y aparecen como un residuo cuantitativo de la sustitución lingüística del siglo pasado. Por consiguiente, la sustitución lingüística (y la aculturación) se ha impuesto - y se impone todavía - como una exigencia del cambio social, y se encuentra en relación con las ocupaciones que tienen más dependencia del dominio formal y escrito del castellano estándar. 
TABLA VIII

Indices compuestos de la actuación comunicativa bilingüe del ámbito familiar en función de la actividad principal del encuestado

\begin{tabular}{|c|c|c|c|c|c|c|c|}
\hline \multirow[b]{2}{*}{ Sectores } & \multicolumn{3}{|c|}{ Relación paterna } & \multicolumn{3}{|c|}{ Relación filial } & \multirow[b]{2}{*}{$\begin{array}{l}\text { Índice } \\
\text { comp. }\end{array}$} \\
\hline & Padre & Madre & $\begin{array}{l}\text { Entre } \\
\text { ellos }\end{array}$ & Hijo & $\mathrm{Hija}$ & Pareja & \\
\hline Agric./Ganad. & 3.1 & 3.1 & 3.1 & 3 & 3.2 & 2.9 & 3 \\
\hline indust./Tall. & 2.4 & 2.4 & 2.5 & 2.3 & 2.4 & 2.2 & 2.3 \\
\hline Construcción & 2.1 & 2.1 & 2.1 & 2.2 & 2 & 1.9 & 2 \\
\hline Comercio & 2.4 & 2.4 & 2.4 & 2.2 & 2.2 & 2.1 & 2.2 \\
\hline Servicios & 2.2 & 2.1 & 2.3 & 2.1 & 2 & 2 & 2.1 \\
\hline Ama de casa & 2.3 & 2.4 & 2.4 & 2.2 & 2.2 & 2.2 & 2.2 \\
\hline Estudiante & 2.1 & 2.2 & 2.3 & - & - & 1.8 & 2.1 \\
\hline TOTAL & 2.3 & 2.3 & 2.4 & 2.3 & 2.3 & 2.2 & 2.3 \\
\hline
\end{tabular}

3.6. La actuación comunicativa bilingüe del ámbito de intercambio económico en función de las regiones valencianas contrasta fuertemente con la correspondiente actuación comunicativa bilingüe del ámbito familiar. Aunque los indices compuestos suponen en este caso una pequeña inadecuación respecto a los porcentajes, he acudido a ellos por ofrecernos una visión general de este ámbito a nivel descriptivo y significar una estimación de error mínimo (vid. tabla IX). Los índices compuestos ponderados de actuación bilingüe del ámbito de intercambio económico nos distinguen sólo dos zonas: a) área de bilingüismo activo con predominio del castellano oral sobre el valenciano: Alcoi-Gandia (índice compuesto de 2.4), Castelló (2.1) y València (2), y b) área de bilingüismo pasivo con dominio del castellano: Alacant (índice compuesto de 1.4), Oriola (1) y Requena-Sogorb (1).

3.7. En suma, la situación sociolingüistica actual de las comunidades de habla alicantinas en función de la actuación comunicativa bilingüe viene determinada cualitativamente por las normas de uso de los individuos dentro del ámbito familiar y del intercambio económico, de manera que las dos áreas alicantinas delimitadas a partir del primero se reducen a una en el segundo. La sustitución lingüistica se ha verificado en general dentro de las relaciones económicas y formales en la región de Alacant. La sustitución lingüística (y la aculturación) se ha impuesto -y 
TABLA IX

Indices compuestos de la actuación comunicativa bilingüe del ámbito de intercambio económico en función de las regiones valencianas

(ordenadas de mayor a menor)

\begin{tabular}{lccccc}
\hline Regiones & Comercios & Almacenes & $\begin{array}{c}\text { Banco: reg. } \\
\text { hablado }\end{array}$ & $\begin{array}{c}\text { Banco: reg. } \\
\text { escrito }\end{array}$ & $\begin{array}{c}\text { Indice } \\
\text { comp. }\end{array}$ \\
\hline Alcoi-Gandia & 3.1 & 2.3 & 3 & 1.2 & 2.4 \\
Castelló & 2.7 & 2.1 & 2.6 & 1.2 & 2.1 \\
València & 2.5 & 2.1 & 2.4 & 1.1 & 2 \\
Alacant & 1.7 & 1.4 & 1.6 & 1 & 1.4 \\
Oriola & 1.1 & 1 & 1 & 1 & 1 \\
Requena-Sogorb & 1 & 1 & 1 & 1 & 1 \\
\hline TOTAL & 2.1 & 1.8 & 2.1 & 1.1 & 1.7 \\
\hline
\end{tabular}

se impone aún - en la comunidad de habla alicantina propiamente dicha como una exigencia del cambio social, y se encuentra en relación con la socialización y educación de los hijos y con las ocupaciones que tienen más dependencia del dominio formal y escrito del castellano estándar. Con todo, la situación sociolingüística es hoy más compleja e inestable que nunca, en vista de la recatalanización creciente del País Valenciano.

\section{Actitudes lingüísticas negativas}

Aunque la problemática sociolingüística puede parecer que reside en la regresión de una competencia comunicativa activa en pasiva, la auténtica dimensión subyacente del hecho de la frontera lingüistica catalano-castellana es la cuestión sociolingüística de las actitudes lingüisticas y de la inseguridad lingüistica. En este sentido, el conflicto lingüístico valenciano se manifestaría en una actitud lingüística negativa de las comunidades de habla alicantinas hacia los vernáculos valencianos (valenciano y valenciano alicantino) ${ }^{9}$. El valenciano (ali-

9 En la encuesta se evitó dicha diferenciación, ya que en general no es subjetivamente apreciable, y nos exigirá un análisis más complejo y multidimensional. Hace ya algunos años, Menéndez Pidal (1923, p. 446) escribía sa variedad idiomática del antiguo reino de Valencia, catalana, histórica y lingüísticamente, ha sido considerada con frecuencia como 
cantino) sería el sociolecto marcado por el estigma social en el contexto valencianohablante de la comunidad de habla alicantina propiamente dicha. El castellano estándar sería el sociolecto no marcado en el contexto valencianohablante y murcianohablante de las comunidades de habla alicantinas. Por consiguiente, la jerarquización de funciones caracterizaría esta fase multilingüe del conflicto lingüístico, y suscitaria la oposición sociolingüistica castellano estándarlvalenciano (alicantino).

En un sentido amplio, caracterizamos la actitud lingüistica como un modelo hipotético directamente relacionado con el comportamiento lingüístico o con las respuestas verbales a cualquier conjunto de estímulos. La actitud se determina mediante un índice afectivo, cognitivo o conativo de las reacciones evaluativas hacia las diferentes variedades lingüísticas, una variable sociolingüística de una lengua dada, el uso de una variedad determinada en un ámbito específico o hacia una lengua como marcador de grupo. Las medidas técnicas de las actitudes linguísticas pueden ser calificadas de análisis de contenido del tratamiento social, medidas directas e indirectas. En nuestro caso, la encuesta se ha limitado a medidas directas, que observan las actitudes lingüísticas a partir de una serie de cuestiones directas en entrevistas personales ${ }^{10}$. El criterio de prestigio ha sido manejado frecuentemente como vector que impele al cambio de norma y sustitución lingüística, aunque debe ser especificado empiricamente en función del propio grupo de hablantes y del contexto implicado.

4.1. La actitud lingüística hacia el registro hablado valenciano en función de las regiones valencianas aparece analizada en el índice de aceptabilidad activa (pregunta $n .^{\circ} 19 a$, vid. tabla $X$ ) y de aceptabilidad pasiva (pregunta $n^{\circ} 19 \mathrm{~b}$, vid. tabla $\mathrm{XI}$ ) "' $\mathrm{y}^{\prime}$ en los indices compuestos

una lengua per se por los habitantes de la región. La explicación de este hecho, que hasta ahora no ha sabido encontrar la ciencia, debe buscarse seguramente en el hondo sentimiento de amor hacia la terreta que caracteriza a los valencianos». En nuestros días, Ninyoles (1972, pp. 170 ss.) ha estudiado sucintamente la naturaleza y función de ese prejuicio lingüístico de acuerdo con los principios de reduccionismo, disimetria e idealización del propio proceso del conflicto psicológico individual, en correlación con el fenómeno de identificación con el grupo cultural dominante (vid. Mollà, 1982; Pitarch, 1984, pp. 45 ss.).

10 La relativa validez de medidas directas e indirectas debe estimular el reconocimiento adyacente de la relación que existe entre ambos tipos de métodos (vid. Agheyisi y Fishman, 1970; Cooper y Fishman, 1974; López Morales, 1979; Ryan, Giles y Sebastian, 1982; Carranza, 1982; Ros, 1982; Gimeno, 1982a).

11 Dichas preguntas se formularon así: Se sent incòmode quan parla en valencia? - 1 quan el sent parlar?/¿Se siente incómodo cuando habla en valenciano? - ¿Y cuando lo oye hablar? Las respuestas se limitaron a: Si, no i no sap o no contesta/Si, no y no sabe o no 
de las actitudes en el ámbito de uso público (preguntas n ${ }^{\circ s}$ 23a, 25a, 25 c y $27 a$, vid. tabla XII) ${ }^{12}$. En las primeras (tablas X y XI), el grado descriptivo de tolerancia activa del valenciano es, en lineas generales, inferior al de tolerancia pasiva. Mientras que el grado de aceptabilidad activa en la región de Alacant es bajo y muestra una cierta intolerancia activa minoritaria (índice simple de .6), el nivel de aceptabilidad pasiva es alto y señala la tolerancia pasiva del valenciano (índice de .8). La región de Oriola ofrece el mayor porcentaje de intolerancia pasiva del valenciano $(43 \%)$, aunque la mayoría lo acepta pasivamente (53\%). Su índice de aceptabilidad pasiva es la única del País Valenciano que se mueve entre coordenadas de tolerancia e intolerancia hacia el valenciano (.5). Asimismo hay intolerancia activa hacia el valenciano (índice de .2).

La hipótesis nula de independencia puede ser rechazada con toda seguridad (probabilidad muy inferior a .001), y, por consiguiente, la dependencia entre la actitud respecto del grado de tolerancia activa o pasiva del valenciano y los hablantes de las regiones de Alacant y Oriola es bien real. Por otro lado, las diferencias entre las proporciones de población de los hablantes de la región de Alacant que rehúsan (o no) activa o pasivamente el valenciano son ambas estadísticamente significativas: «sí»-«no» activas $(-.38 ;-.02)$ y «sí»-«no» pasivas $(-.84$; -.58) para un nivel de confianza del $95 \%$. Sin embargo, las diferencias entre las proporciones de población de los hablantes de la región de Oriola que rehúsan (o no) activa o pasivamente el valenciano no son uniformes, de manera que es estadísticamente significativa la intolerancia activa hacia el valenciano $(.47 ; .81)$, pero no lo es la intolerancia pasiva $(-.31 ; .11)$, para el mismo nivel de confianza del $95 \%$. Asimismo, las diferencias entre las proporciones de población de los hablantes de las regiones de Alacant u Oriola que rehúsan (o no) activa o pasiva-

contesta. He asignado los valores de 0 y 1 a si y no, respectivamente. Las frecuencias de no sap o no contesta/no sabe o no contesta se han inciuido dentro de los cálculos estadísticos en el primer caso (aceptabilidad activa) y no en el segundo (aceptabilidad pasiva), de acuerdo con una interpretación de probable pertinencia y como valoraciones negativas en su caso.

12 Dichas preguntas se formularon asi: Que el valencià es parle a l'escolalen l'Administraciólen el seu Ajuntamentien els actes oficials, vosté considera que és:/¿Cómo considera el hablar valenciano en las siguientes situaciones? En la escuela/En la administración/En su ayuntamiento/En actos oficiales. Las respuestas se limitaron a: Necessari, important, convenient, ridicul, indiferent i no sap o no contesta/Necesario, importante, conveniente, ridiculo, indiferente y no sabe o no contesta. Hemos utilizado la escala valorativa siguiente: Necessari/Necesario (3 puntos), important/importante (2), convenient/conveniente (1), ridicul/ridiculo (-1) e indiferentindiferente (0). Las frecuencias de no sap o no contesta/no sabe o no contesta no se han incluido en los cálculos estadísticos. Las valoraciones de «indiferencia» se consideran negativas, desde un punto de vista de lealtad lingüistica. 
mente el valenciano son todas ellas estadísticamente significativas: "sí" activas $(-.21 ;-.01)$, «no» activas $(.19 ; .35)$, «sí» pasivas $(-.17 ;-.03)$ y «no» pasivas $(.16 ; .38)$, para el mismo nivel de confianza del $95 \%$.

\section{TABLA X}

Indices de aceptabilidad activa hacia el registro hablado valenciano en función de las regiones valencianas (ordenadas de mayor a menor)

\begin{tabular}{|c|c|c|c|c|c|c|c|c|}
\hline \multirow[b]{2}{*}{ Regiones } & \multirow[b]{2}{*}{ Total } & \multicolumn{2}{|c|}{ Sí } & \multicolumn{2}{|c|}{ No } & \multicolumn{2}{|c|}{ NS/NC } & \multirow[b]{2}{*}{ Índice } \\
\hline & & $\mathbf{N}$ & $\%$ & $\mathbf{N}$ & $\%$ & $\mathbf{N}$ & $\%$ & \\
\hline Alcoi-Gandia & 229 & 12 & 5 & 204 & 89 & 13 & 6 & .9 \\
\hline Castelló & 228 & 15 & 7 & 187 & 82 & 26 & 11 & .8 \\
\hline València & 480 & 45 & 9 & 340 & 71 & 95 & 20 & .7 \\
\hline Alacant & 283 & 40 & 14 & 171 & 60 & 72 & 25 & .6 \\
\hline Requena-Sogorb & 181 & 35 & 19 & 40 & 22 & 106 & 59 & .2 \\
\hline Oriola & 204 & 19 & 9 & 37 & 18 & 148 & 73 & .2 \\
\hline TOTAL & 1.605 & 166 & 10 & 979 & 61 & 460 & 29 & .6 \\
\hline
\end{tabular}

TABLA XI

Indices de aceptabilidad pasiva hacia el registro hablado valenciano en función de las regiones valencianas (ordenadas de mayor a menor)

\begin{tabular}{lrrrrrrrrr}
\hline & & \multicolumn{3}{c}{ Si } & \multicolumn{2}{c}{ No } & \multicolumn{2}{c}{ NS/NC } & \\
\cline { 3 - 8 } Regiones & Total & N & $\%$ & N & $\%$ & N & $\%$ & Indice \\
\hline Alcoi-Gandia & 229 & 8 & 3 & 217 & 95 & 4 & 2 & .9 \\
Castelló & 228 & 10 & 4 & 217 & 95 & 1 & 0 & .9 \\
València & 480 & 24 & 5 & 443 & 92 & 13 & 3 & .9 \\
Alacant & 283 & 40 & 14 & 240 & 85 & 3 & 3 & .8 \\
Requena-Sogorb & 181 & 48 & 27 & 127 & 70 & 6 & 3 & .7 \\
Oriola & 204 & 88 & 43 & 108 & 53 & 8 & 4 & .5 \\
\hline TOTAL & 1.605 & 218 & 14 & 1.352 & 84 & 35 & 2 & .8 \\
\hline
\end{tabular}


Por su parte, en la tabla XII y a nivel descriptivo es perceptible en la región de Alacant una actitud lingüística negativa hacia el uso del registro hablado valenciano en el ámbito público (escuela, administración pública, ayuntamiento y actos oficiales). El índice compuesto de dicha región es muy inferior a la ponderación general de una actitud lingüística positiva hacia el uso del valenciano en el ámbito público $(.5$ frente a .9, respectivamente). Sólo en el ámbito específico de la escuela aparece una actitud lingüística más próxima a dicha general, si bien es inferior al índice correspondiente de la región castellanohablante de Requena-Sogorb (.7 y 1). La región de Oriola presenta la menor valoración de la actitud lingüística hacia el uso del valenciano en el ámbito público, y es abiertamente negativa (índice compuesto de -.1). En la escuela también aparece una actitud lingüística menos negativa (.3).

\section{TABLA XII}

Indices compuestos de las actitudes lingüisticas hacia el uso del registro hablado valenciano en el ámbito público, en función de las regiones valencianas (ordenadas de mayor a menor)

\begin{tabular}{lccccc}
\hline Regiones & Escuela & Administ. & Ayuntam. & Actos oficial. & $\begin{array}{c}\text { Índice } \\
\text { comp. }\end{array}$ \\
\hline Alcoi-Gandia & 1.7 & 1.4 & 1.4 & 1.5 & 1.5 \\
València & 1.8 & 1.3 & 1.4 & 1.5 & 1.5 \\
Castelló & 1.5 & 1 & 1 & 1.2 & 1.2 \\
Alacant & .7 & .5 & .5 & .5 & .5 \\
Requena-Sogorb & 1 & .2 & .2 & .2 & .4 \\
Oriola & .3 & -.2 & -.3 & -.2 & -.1 \\
\hline TOTAL & 1.3 & .8 & .8 & .9 & .9 \\
\hline
\end{tabular}

4.2. Finalmente, las actitudes lingüísticas hacia la utilización del valenciano en los medios de comunicación social (prensa, radio y televisión regional) en función de las regiones valencianas nos muestran descriptivamente una valoración general más homogénea (preguntas $n^{\circ 5} 29 a, 29 \mathrm{c}$ y $29 \mathrm{e}$, vid. tabla XIII) ${ }^{13}$. El índice compuesto de las actitudes lingüísticas en la

13 Dichas preguntas se formularon asi: Que el valencià s'utilitze en els mitjans de comunicació (premsa/ràdio/Aitana), vosté considera que és:/lic Cómo considera la utilización 
región de Alacant ofrece una cierta actitud negativa minoritaria, y es muy inferior al índice general del País Valenciano, plenamente positivo (.6 frente a 1, respectivamente). El índice simple de la utilización especifica del valenciano en la prensa es el más negativo (.5). Una vez más, la región de Oriola presenta el menor índice compuesto de las actitudes lingüisticas hacia la utilización del valenciano en los medios de comunicación social, y es claramente negativo (0).

\section{TABLA XIII}

Indices compuestos de las actitudes lingüisticas hacia la utilización del valenciano en los medios de comunicación social, en función de las regiones valencianas (ordenadas de mayor a menor)

\begin{tabular}{lcccc}
\hline Regiones & Prensa & Radio & TV. regional & $\begin{array}{c}\text { Indke } \\
\text { comp. }\end{array}$ \\
\hline València & 1.6 & 1.6 & 1.6 & 1.6 \\
Alcoi-Gandia & 1.5 & 1.5 & 1.6 & 1.5 \\
Castelló & 1.2 & 1.3 & 1.3 & 1.3 \\
Alacant & .5 & .6 & .6 & .6 \\
Requena-Sogorb & .4 & .4 & .4 & .4 \\
Oriola & 0 & 0 & 0 & 0 \\
\hline TOTAL & 1 & 1 & 1 & 1 \\
\hline
\end{tabular}

4.3. En suma, la verdadera dimensión subyacente del hecho de la frontera lingüística catalano-castellana en las comunidades de habla alicantinas es la cuestión sociolingüística de las actitudes lingüísticas, que también forman parte esencial de la competencia comunicativa de los hablantes y de las comunidades de habla. El conflicto lingüistico valenciano viene determinado así por unas actitudes lingüísticas negativas que se manifiestan en ciertas coordenadas de intolerancia activa minoritaria (región de Alacant) y una intolerancia activa y pasiva (región de Orio/a) hacia el valenciano, y en las menores valoraciones respecto del uso y utilización del valenciano en el ámbito público. La dinámica sociolingüística comienza precisamente aquí. Actitudes lingüísticas negativas

del valenciano en los medios de comunicación (prensalradiolAitana)? Las respuestas y valoraciones fueron las mismas que se han dado en la nota anterior. 
(e inseguridad lingüística) constituyen un poderoso motor del cambio de norma y de la sustitución lingüística. El conflicto de lealtad lingüistica afecta a la inteligibilidad mutua y a la sustitución lingüística valenciana del ámbito familiar.

\section{Conclusiones}

La situación diglósica de las comunidades de habla alicantinas (y del País Valenciano) responde a un conflicto lingüístico (y aculturación), que se generó en el remoto pasado, probablemente desde el siglo XV. Dicho conflicto ofrece hoy el proceso de regresión -histórica, geográfica, social y situacional- del valenciano en las transiciones de la oposición sociolingüística castellano estándar/valenciano alicantino y castellano estándarimurciano alicantino.

5.1. Cualquier hablante de las comunidades de habla alicantinas (y del País Valenciano) es básicamente multilectal. Y la auténtica dimensión del proceso de homologación lingüístico-cultural se manifiesta a través de la cuestión sociolingüística de las actitudes lingüisticas. El valenciano (alicantino) y el murciano (alicantino) son los sociolectos marcados socialmente en el contexto valencianohablante y murcianohablante - respectivamente- de las comunidades de habla alicantinas. El castellano estándar es el sociolecto no marcado en cualquier contexto de dichas comunidades, aunque actualmente se encuentra dentro de una situación más compleja y fecunda que la propia del pasado inmediato con su condición de lengua oficial única.

El modelo de preferencia lingüistica en las comunidades de habla alicantinas puede calificarse, pues, de "preferencia del exogrupo", en el que los hablantes de ambas variedades lingüísticas reconocen la superioridad de la variedad lingüística del grupo dominante o exogrupo (castellano estándar), con respecto tanto a poder social como a valores de solidaridad de grupo. Una planificación lingüistica del valenciano en las comunidades de habla alicantinas comporta necesariamente una corrección de las actitudes lingüísticas y programas de inmersión lingüística.

5.2. Las comunidades de habla alicantinas son multilectales, y se basan en una covariación entre los dos (sub)sistemas de un único repertorio lingüístico. No obstante, la presencia de un haz de isoglosas reagrupa diáfanamente las variedades catalanas frente a las castellanas. El monolingüismo catalán o castellano, en términos absolutos, es prácticamente inexistente, y las comunidades de habla alicantinas res- 
ponden más a un esquema comunicativo de multilectismo que a dos comunidades idiomáticas monolingües.

La sustitución lingüística valenciana de las comunidades de habla alicantinas está en función de los diferentes ámbitos de uso, y se ha verificado en general dentro de las relaciones económicas y formales en la comunidad de habla alicantina propiamente dicha. La sustitución lingüistica (y la aculturación) se ha impuesto - y se impone aún-en el ámbito familiar como una exigencia del cambio social, y se encuentra en relación con la socialización y educación de los hijos, y con las ocupaciones que tienen más dependencia del dominio formal y escrito del castellano estándar.

\section{Referencias bibliográficas}

Agheyisi, R. y Fishman, J. A. (1970), «Language Attitude Studies», Anthropological Linguistics, 12, pp. 137-57.

Alcover, A. M. (1908), «El català devant els filòlecs estranjers. Una mica de dialectologia catalana", Bolletí del Diccionari de la Llengua Catalana, IV, pp. 194-303.

Alpera, LI. (1969), "Conciencia y normalización lingüística en el País Valenciano", en Filología y crítica hispánica iHomenaje al prof. $F$. Sánchez Escribano), Madrid, pp. 335-45.

- (1981) «Cap a una interpretació sociolingüística i semàntica dels problemes d'interferències $i$ de substitucions lèxiques en el valencià meridional», Item, 5, pp. 93-106.

Alvar, M. (1955/1971), La frontera catalano-aragonesa, Zaragoza: Institución «Fernando el Católico», 1976.

- (1969), Estructuralismo, geografia lingüistica y dialectología actual, 2. ${ }^{2}$ edn., Madrid: Gredos, 1973.

Amastae, J. (1981), «Learner Continuums and Speech Communities», Papers in Linguistics, 14, 2, pp. 155-96.

Aracil, Ll. V. (1965), Conflit linguistique et normalisation linguistique dans l'Europe nouvelle, Reed., Perpignan: I.R.S.C.E., 1976.

- (1966), «Un dilema valencià», Identity Magazine, 24, pp. 17-29.

- (1968), «Introducció", en Escalante, E., Les xiques de l'entresuelo i Tres forasters de Madrid, València: Garbi, pp. 7-88.

- (1979), «Educació i sociolingüística», Treballs de Sociolingüistica Catalana, 2, pp. 33-86.

- (1983), Dir la realitat, Barcelona: Països Catalans.

Badia, A. M. (1977), «Lenguas en contacto: Bilingüismo, diglosia, lenguas en convivencia», en Lapesa, R. (coord.), Comunicación y lenguaje, Madrid: Karpos, pp. 10-33. 
Badia, A. M. (1981), La formació de la llengua catalana. Assaig d'interpretació historica, Barcelona: Abadia de Montserrat.

Bailey, Ch.-J. N. (1972), «La integración de la teoría lingüística: Reconstrucción interna y el método comparado en el análisis descriptivo", en Stockwell, R. P. y Macaulay, R. K. S. (eds.), Cambio lingüistico y teoria generativa, Madrid: Gredos, 1977, pp. 49-61.

- (1973), Variation and Linguistic Theory, Arlington: Center for Applied Linguistics.

Barnils, P. (1913), Die Mundart von Alacant. Beitrag zur Kenntnis des Valencianischen, Barcelona: Biblioteca Filològica de l'Institut de la Llengua Catalana.

- (1914), "Comentaris a la flexió alacantina», BDC, II, pp. 24-33.

- (1929), «Més materials de contribució a l'estudi del català d'Alacant», $B D C$, XVII, pp. 51-6.

Berdan, R. (1977), «Polylectal Comprehension and the Polylectal Grammar", en Fasold, R. W. y Shuy, R. W. (eds.), Studies in Language Variation, Washington, D. C.: Georgetown University, pp. 12-29.

Bickerton, D. (1973), "The Structure of Polylectal Grammars", en Shuy, R. W. (ed.), Sociolinguistics: Current Trends and Prospects (23rd Round Table Meeting), Washington, D. C.: Georgetown University, pp. 17-42.

- (1975), Dynamics of a Creole System, Cambridge: Cambridge University.

Carranza, M. A. (1982), «Attitudinal Research on Hispanic Language Varieties", en Ryan, E. B. y Giles, H. (eds.), Attitudes toward Language Variation. Social and Applied Contexts, London, pp. 63-83.

Colomina, J. (1984a), «La generalització de la pèrdua de la /d/ intervocàlica en el valencià meridional alacantí», Anales de la Universidad de Alicante. Escuela de Magisterio, 1, pp. 173-202.

- (1984b), «El parlar de la Canyada de Biar (l'Alt Vinalopó): un estudi de sociolingüistica», Quaderns de Filologia (Miscel.lània Sanchis Guarner), I, pp. 81-7.

- (1985a), L'alacantí. Un estudi sobre la variació lingüistica, Alacant: Diputació Provincial.

- (1985b), «El parlar de la Marina Alta», La Rella, 4, pp.37-54.

- (1986), «El parlar del Camp d'Alacant», Actes del / Congrés d"Estudis del Camp d'Alacant, Alacant (en prensa).

Cooper, R. L. y Fishman, J. A. (1974), "The Study of Language Attitudes", International Journal of the Sociology of Language, $3, \mathrm{pp}$. 5-19. 
Fishman, J. A. (1968), «Conservación y desplazamiento del idioma como campo de investigación (Reexamen)", en Garvin, P. L. y Lastra, Y. (eds.), Antología de estudios de etnolingüistica y sociolingüistica, México: UNAM, 1974, pp. 375-423.

Fishman, J. A., Cooper, R. L., Ma, R. et al. (1971), Bilingualism in the Barrio, 2. ${ }^{a}$ edn., Bloomington: Indiana University, 1975.

Fuster, J. (1962), Nosaltres els valencians, 2. ${ }^{a}$ edn., Barcelona: Edicions $62,1964$.

Gal, S. (1979), Language Shift. Social Determinants of Linguistic Change in Bilingual Austria, New York: Academic Press.

Gimeno, F. (1975), Sociolingüística catalana: El habla marinera de Santa Pola, 2 vols. Tesis doctoral, Universidad de Murcia (inédita).

- (1977), «Introducción a la sociolingüística», Item, 2, pp. 53-65.

- (1979), “Sociolingüistica: Un modelo teórico», Boletín de la Academia Puertorriqueña de la Lengua Española, 7, 1, pp. 125-68.

- (1981), "Dimensiones del multilingüismo", Revista Española de Lingüistica, 11, 2, pp. 341-73.

- (1982a), «Alternatives al bilingüisme valencià meridional: A propòsit d'una pre-enquesta sobre les actituds lingüístiques", Treballs de Sociolingüística Catalana, 4, pp. 51-61.

- (1982b), «Aproximación sociolingüística a la comunidad de habla valenciana meridional», en Ninyoles, R. LI. et al., Estructura social al País Valencià, València: Diputació, pp. 725-37.

- (1983a), «Hacia una sociolingüística histórica», Estudios de Lingüistica de la Universidad de Alicante, 1, pp. 181-226.

- (1983b), «El seseo valenciano de la comunidad de habla alicantina», Anales de Literatura Española de la Universidad de Alicante, 1 (1982), pp. 345-62.

- (1984a) "Vers una sociolingüística històrica?", Treballs de Sociolingüistica Catalana, 5 (1983), pp. 53-70.

- (1984b) «El sustrato lingüístico y el seseo valenciano de la comunidad de habla alicantina», Quaderns de Filologia (Miscel-lània Sanchis Guarner), I, pp. 139-46.

- (1985), «Multilingüismo y multilectismo», E.L.U.A., 2 (1984), pp. 61-89.

- (1986a) «Llengua, cultura i societat a Alacant», en Miscel/lània A. M. Badia, IV, Barcelona: Abadia de Monserrat, pp. 171-89.

- (1986b) «A propósito de comunidad de habla: "The Social Dimension of Dialectology» de J. P. Rona», Actas de I Congreso Internacional sobre el Español de América, San Juan de Puerto Rico (en prensa). 
Gimeno, F. (1987), «El español como diasistema multilectal», Actas del III Simposio Internacional de Lengua Española, Las Palmas de Gran Canaria (en prensa).

Gómez, J. R. (1984), Niveles sociolingüísticos de Sagunto. Análisis de las interferencias morfosintácticas en la comunidad de habla de Sagunto (Valencia), 2 vols., Tesis doctoral, Universidad de Valencia (inédita).

Guillén, J. (1974), El habla de Orihuela, Alicante: Diputación Provincial. Heidelberger Forschungsprojekt «Pidgin-Deutsch" (1978), "The Acquisition of German Syntax by Foreign Migrant Workers", en Sankoff, D. (ed.), Linguistic Variation, New York: Academic Press, pp. $1-22$.

Johnson, R. A. y Wichern, D. W. (1982), Applied Multivariate Statistical Analysis, Englewood Cliffs, New Jersey: Prentice-Hall.

Juan i Fenollar, R. (1981), "Comarques: Qüestions a debatre», en Ninyoles, R. et. al., Estructura social al País Valencià, València, 1982, pp. 227-58.

Labov, W. (1972), Modelos sociolingüísticos, Madrid: Cátedra, 1984.

Lapesa, R. (1942/1980), Historia de la lengua española, 8. ${ }^{\text {a edn., Ma- }}$ drid: Gredos.

López Morales, H. (1979), «Velarización de /RR/ en el español de Puerto Rico: Indices de actitudes y creencias», en Dialectología y sociolingüística. Temas puertorriqueños. Madrid: Hispanova de Ediciones, pp. 107-30.

- (1983), Estratificación social del español de San Juan de Puerto Rico, México: UNAM.

Mateo, J. V. (1966), Alacant a part, Barcelona: Mediterrània Edicions.

Menéndez Pidal, R. (1908), "Sobre los limites del valenciano. A propósito de J. Hadwiger: Sprachgrenzen und Grenzmundarten des Valencianischen, ZRPh, XXIX, 712-731", en Primer Congrés Internacional de la Llengua Catalana, Barcelona, pp. 340-4.

- (1923), «Filología (Idiomas y dialectos españoles)», en Enciclopedia de Espasa, s.v. España, XXI, Barcelona, pp. 413-50.

Milroy, L. (1980), Language and Social Networks, Oxford: Balckwell.

- (1982), "Social Network and Linguistic Focusing", en Romaine, S. (ed.), Sociolinguistic Variation in Speech Communities, London: E. Arnold, pp. 141-52.

Mira, J. F. (1981), Població i llengua al País Valencià, València: Diputació.

Moliner, J. et al. (1976), Escola i llengua al País Valencià, Valencia: Tres i Quatre.

Mollà, J. D. (1982), "Sobre la estructura de clases del País Valenciano», 
en Ninyoles, R. Ll. et al., Estructura social al Pais Valencià, València, pp. 587-97.

Mollà, D., Alpera, LI., Gimeno, F. et al. (1985), Estudi sociològic sobre la problemàtica sociolingüistica a la Comunitat Valenciana, 4 vols., Conselleria de Cultura, Educació i Ciència de la Generalitat Valenciana (inédito).

Montoya, B. (1982), "Los islotes lingüísticos de Aspe y Elda en el Vinalopó Medio", Revista del Instituto de Estudios Alicantinos, 35, pp. 119-34.

- (1984), «Alguns problemes d'interferència lèxico-semàntica en una comunitat de parla multilectal», Quaderns de Filologia (Miscel-lània Sanchis Guarner), I, pp. 235-40.

- (1985), De sociolingüistica històrica: Canvi lingüistic en curs i desplaçament de llengües a l'extrem meridional de la llengua catalana, 2 vols., Tesis doctoral, Universidad de Alicante (inèdita).

- (1986a), «Al voltant de la substitució i el canvi lingüístics. Els casos d'Elx i Alacant durant la segona meitat del segle XIX", Treballs de Sociolingǘstica Catalana, 6 (en prensa).

- (1986b), "Variabilitat i canvi en el parlar alacantí a les darreries del segle XIX", Actes del I Congrés d'Estudis del Camp d'Alacant, Alacant (en prensa).

Ninyoles, R. LI. (1972), Idioma y poder social, Madrid: Tecnos.

- (1976a), "Idéologies diglossiques et assimilation", en Ninyoles, R. Ll. et al., Estructura social al País Valencià, València, 1982, pp. 669-77.

- (1976b), Bases per a una política lingüística democràtica a l'Estat espanyol, València: Tres i Quatre.

- (1977), Cuatro idiomas para un estado (El castellano y los conflictos lingüisticos de la España periférica), Madrid: Cambio 16.

Nomenclàtor geogràfic del Pais Valencià (1970), València: Promocions Culturals.

Pitarch, V. (1984), «Un cas singular de conflicte lingüistic: la situació actual del País Valencià», Treballs de Sociolingüística Catalana, 5 (1983), pp. 41-51.

Poplack, S. (1986), "The Care and Handling of a Mega-Corpus: The Ottawa-Hull French Project», en Fasold, R. y Shiffrin, D. (eds.), Proceedings of NWAVE XI, Washington, D. C. (en prensa).

Rona, J. P. (1976), «The Social Dimension of Dialectology», International Journal of the Sociology of Language, 9, pp. 7-22.

Ros, M. (1979), "Valores instrumentales e integrativos del valenciano y castellano", en ICE de la Universidad de Valencia (ed.), Jornadas de bilingüismo, Valencia, pp. 85-101. 
Ros, M. (1982), «Percepción y evaluación social de hablantes de cinco variedades lingüísticas», en Ninyoles, R. LI. et al., Estructura social al País Valencià, València, pp. 679-97.

Ryan, E. B., Giles, H. y Sebastian, R. J. (1982), «An Integrative Perspective for the Study of Attitudes toward Language Variation», en Ryan, E. B. y Giles, H. (eds.), Attitudes toward Language Variation. Social and Applied Contexts, London: E. Arnold, pp. 1-19.

Sanchis Guarner, M. (1960), La llengua dels valencians, $4 .^{a}$ edn., València: L'Estel, 1972.

- (1961), "Limits i demarcacions històriques del Regne de València», en Obra completa, I, València: Tres i Quatre, 1976, pp. 87-123.

- (1973), «La frontera lingüística en las provincias de Alicante y Murcia», Cuadernos de Geografia, 13, pp. 15-29.

Sankoff, D. y Labov, W. (1979), «On the Uses of Variable Rules», Language in Society, 8, pp. 189-222.

Sankoff, D. y Poplack, S. (1981), «A Formal Grammar for Code-Switching", Papers in Linguistic, 14, 2, pp. 3-46.

Torreblanca, M. (1976), Estudio del habla de Villena y su comarca, Alicante: Diputación Provincial.

Trudgill, P. (1982), «Sociolinguistics and Linguistic Theory. Polylectal Grammars and Cross-Dialectal Communication", en On Dialect. Social and Geographical Perspectives, Oxford: Blackwell, pp. 8-30.

Turell, M. T. (1984), Elements per a la recerca sociolingüística a Catalunya. El comportament lingüistic a l'àmbit laboral, Barcelona: Edicions 62.

Várvaro, A. (1972/1973), «Storia della lingua: passato e prospettive di una categoria controversa», I (Romance Philology, 26, 1, pp. 16-51) y Il (Romance Philology, 26, 3, pp. 509-31).

Veny, J. (1976), «El valencià meridional», en Estudis de geolingüistica catalana, Barcelona: Edicions 62, 1978, pp. 203-40.

Viedma, J. A. (1972), Exposición intuitiva y problemas resueltos de métodos estadísticos. Fundamentos y aplicaciones, Madrid: Ediciones del Castillo.

Weinreich, U. (1953), Lenguas en contacto. Descubrimientos y problemas, Venezuela: Universidad Central, 1974.

- (1968), unilinguisme et multilinguisme», en Martinet, A. (dir.), Le langage, Paris: Gallimard, pp. 647-83.

Weinreich, U., Labov, W. y Herzog, M. I. (1968), «Empirical Foundations for a Theory of Language Change», en Lehmann, W. P. y Malkiel, Y. (eds.), Directions for Historical Linguistics: A Symposium, Austin: University of Texas, pp. 95-195. 
Weydt, H. y Schlieben-Lange, B. (1981), «Wie realistisch sind Variationsgrammatiken?", en Geckeler, H. et al. (eds.), Logos semantikos (Studia linguistica in honorem E. Coseriu, 1921-81), V, Madrid: Gredos, pp. 117-45.

Zamora Vicente, A. (1960), Dialectología española, 2. ${ }^{a}$ edn., Madrid: Gredos, 1967. 